\title{
Optimization of Comminution Circuit Throughput and Product Size Distribution by Simulation and Control
}

\section{Quarterly Technical Process Report}

Report Period Start Date: $\quad$ October 01, 2002

Report Period End Date: $\quad$ December 31, 2002

Authors:

S. K. Kawatra - Principal Investigator

T. C. Eisele - Engineer/Scientist

H.J. Walqui - Graduate Student

Date of Issue:

January 2003

DOE Award Number:

DE-FC26-01NT41062

Submitting Organization

Department of Chemical Engineering

Michigan Technological University

1400 Townsend Drive

Houghton, Mi 49931 - 1295 


\section{DISCLAIMER:}

This report was prepared as an account work sponsored by an agency of the United States Government. Neither the United States Government nor any agency thereof, nor any of their employees, makes any warranty, express or implied, or assumes any legal liability or responsibility for the accuracy, completeness, or usefulness of any information, apparatus, product, or process disclosed, or represents that its use would not infringe privately owned rights. Reference herein to any specific commercial product, process, or service by trade name, trademark, manufacturer, or otherwise does not necessarily constitute or imply its endorsement, recommendation, or favoring by the United States Government or any agency thereof. The views and opinions of authors expressed herein do not necessarily state or reflect those of the United States Government or any agency thereof. 


\begin{abstract}
The goal of this project is to improve energy efficiency of industrial crushing and grinding operations (comminution). Mathematical models of the comminution process are being used to study methods for optimizing he product size distribution, so that the amount of excessively fine material produced can be minimized. This will save energy by reducing the amount of material that is ground below the target size, and will also reduce the quantity of materials wasted as "slimes" that are too fine to be useful. This will be accomplished by: (1) modeling alternative circuit arrangements to determine methods for minimizing overgrinding, and (2) determining whether new technologies, such as highpressure roll crushing, can be used to alter particle breakage behavior to minimize fines production.

In previous quarters, it was determined that the primary grinding mills were operating at less than full capacity, suggesting that a shift of grinding load to the primary mills could liberate more material before it reached the secondary mills, allowing more complete liberation with a coarser grind. In the eighth quarter, further analysis was carried out to determine the full extent of the benefit that could be obtained by this shift in grinding load. A key part of this analysis was the development of a correlation of the circuit capacity with (a) ore work index, (b) the quantity of primary mill "pebbles" that were crushed by a cone crusher in the circuit, and (c) the fraction of the crushed pebbles that were also processed by a high-pressure roll mill.
\end{abstract}




\section{Table of Contents}

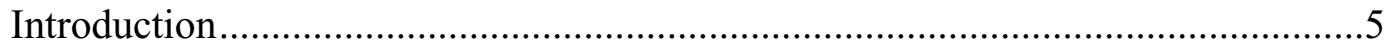

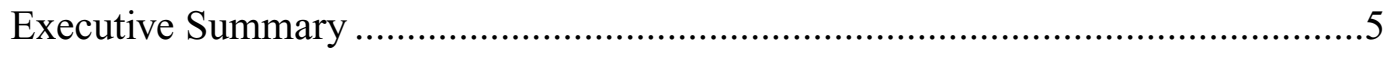

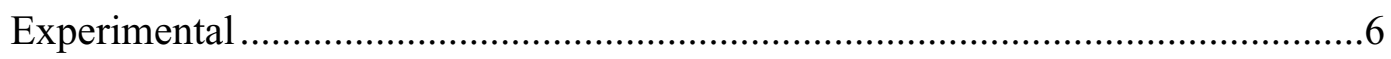

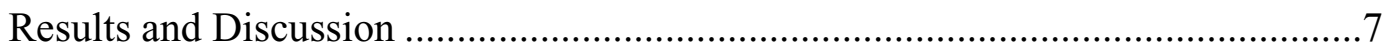

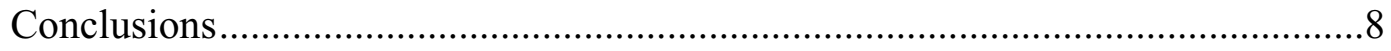

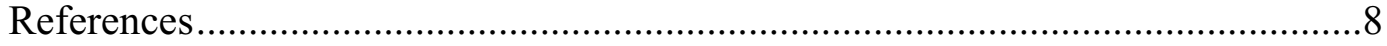

\section{List of Tables and Graphical Materials}

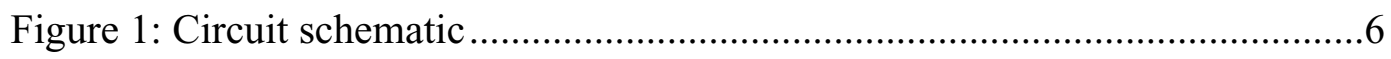

Table 1: Sample of daily plant operating data ................................................... 7

Figure 2: Correlation of circuit throughput with ore characteristics...................... 8 


\section{Introduction}

When grinding iron ore to liberation size, many of the iron oxide particles are ground beyond the size where they are liberated from the silicate grains. This overgrinding of the mineral grains is a significant waste of energy. In order to increase the energy efficiency, this excess grinding must be prevented. The objective of this project is therefore to sample and simulate a full-scale iron ore processing plant to determine methods for increasing grinding circuit energy efficiency by minimizing overgrinding.

\section{Executive Summary}

The goal of this project is to use comminution modeling to study methods for optimizing the product size distribution, so that the amount of excessively fine material produced can be minimized. This will be accomplished by (1) modeling alternative circuit arrangements to determine methods for minimizing overgrinding, and (2) determining whether new technologies, such as high-pressure roll crushing, can be used to alter particle breakage behavior to minimize fines production.

In the previous quarters, analysis of plant samples showed that fine liberated material that should have reported to the overflow instead reported to the underflow and was reground. This is a major source of energy inefficiency in the grinding process. If the magnetite rich fine fraction of the underflow could be recovered before reaching the pebble mill, it would not be overground. The benefits of this would be improved energy efficiency due to reduction in the amount of energy wasted on grinding liberated particles, and increased circuit capacity proportional to the reduction of the amount of material overground. The results of plant sampling and modeling were used to determine whether modifications at points other than the hydrocyclone could allow the magnetite rich fine fraction of the ore to be ground and liberated before reaching the pebble mill. It was determined that the addition of a screening stage between the primary and secondary mills could be used to balance the load between the two types of mills, which would increase throughput and decrease the amount of total grinding that the circuit would need to accomplish.

The next step was determining the amount of load-shifting that could actually be accomplished while still being a benefit. A key requirement for this determination is the development of a correlation between ore properties, circuit operation, and the total capacity of the primary grinding mill. In the current quarter, this correlation was developed from three years of daily plant samples. The resulting expression is currently being used in combination with the previous mathematical models to design effective modifications for the grinding circuit. 


\section{Experimental}

The objective during this quarter was to determine a relationship between feed rate and work index, pebble crushing operating time, and roll press operating time for Empire IV pebble mills. This is needed in order to be able to forecast the mill production from the characteristics of the ore being sent from the mine. Since the work index is a measure of the energy required to grind the ore, and the mills can only apply a limited amount of energy, increasing work index will result in lower mill throughput. The roll press and pebble crusher provide a means for increasing the energy input to the circuit, and so increasing operating time for these units will increase mill throughput.

A simplified flowsheet for the circuit is shown in Figure 1, which includes the pebble crushers and the high pressure grinding roll press.

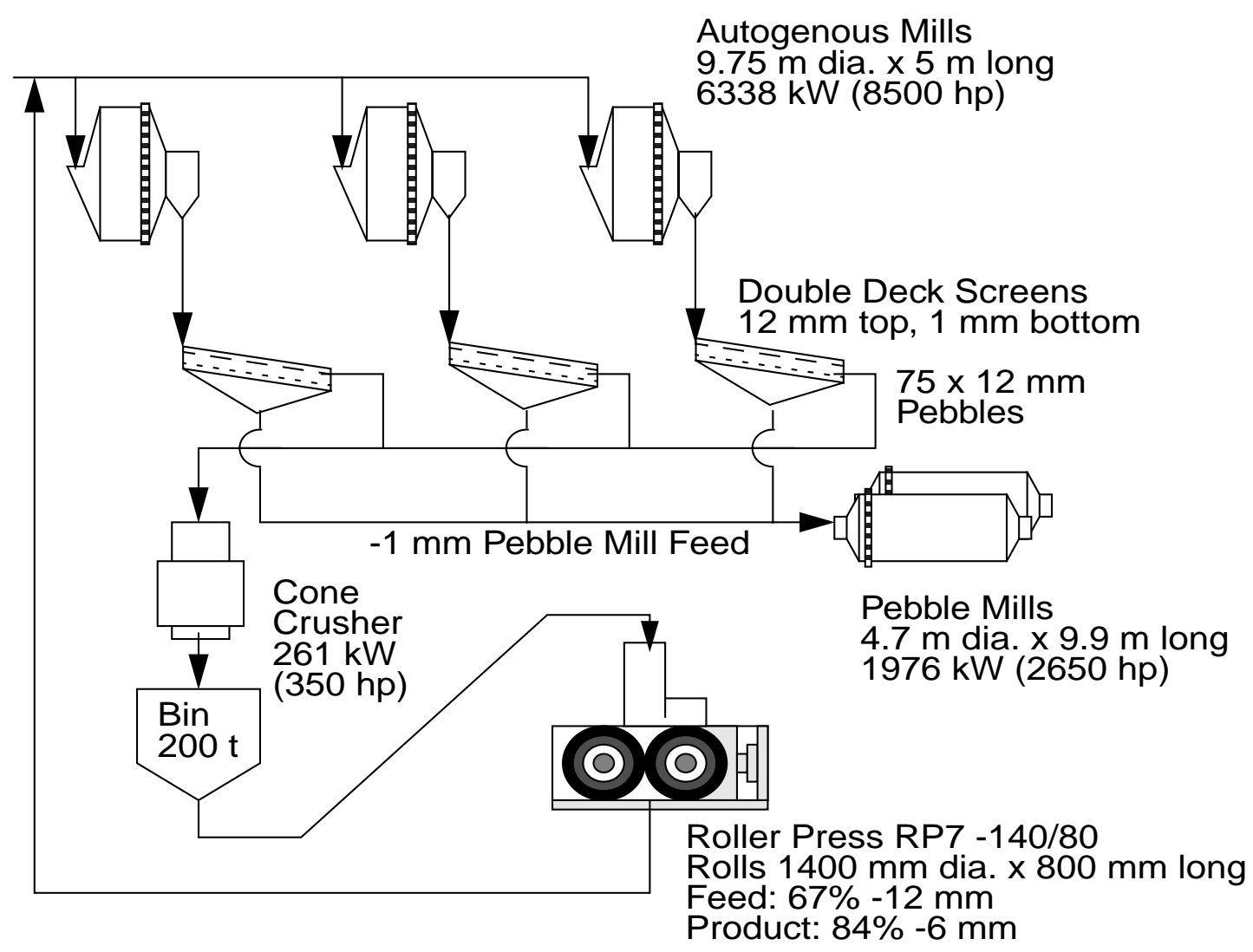

Figure 1: Current primary grinding flowsheet schematic, showing the high pressure grinding rolls and pebble crusher. Addition of the crusher and rolls has increased the primary mill capacity, but has had little effect on the secondary pebble mills. 
Daily plant data was available from the E-view system, which was used to compile data corresponding to the time frame under study. After the data was converted to an MS Excel format, the base data for the relationship had to be sorted.

The following linear equation was selected for the correlation, based on previous observations of the circuit behavior by the plant engineers:

$\mathrm{FR}=(\mathrm{A} * \mathrm{Wi})+\left(\mathrm{B}^{*} \mathrm{PC}_{\mathrm{OT}}\right)+\left(\mathrm{C}^{*} \mathrm{RC}_{\mathrm{ot}}\right)+\mathrm{D}$

Where:

FR: feed rate

Wi: Work index

$\mathrm{PC}_{\mathrm{OT}}$ : Pebble crusher operating time

$\mathrm{RO}_{\mathrm{OT}}$ : Roll crusher operating time

A, B, C, D: Constants

An example of the type of base data used can be seen in the following table (table 1).

Table 1: Daily values corresponding to plant operating conditions.

\begin{tabular}{|c|c|c|c|c|c|c|}
\hline Date & New Side & Operating & Lines 22-24 & Work & E-IV PC & Roll Press \\
\cline { 2 - 7 } & Tons & Time & Feed Rate & Index & Op Time & Op Time \\
\hline $8 / 1 / 02$ & 17,931 & 90.64 & 285.53 & 11.96 & & \\
\hline $8 / 2 / 02$ & 16,261 & 86.61 & 283.79 & 10.93 & & \\
\hline $8 / 3 / 02$ & 19,350 & 90.28 & 276.82 & 12.34 & 25.42 & \\
\hline $8 / 4 / 02$ & 21,428 & 93.33 & 297.61 & 13.76 & 90.42 & 9.17 \\
\hline $8 / 5 / 02$ & 20,657 & 91.25 & 289.72 & 12.15 & 22.08 & 17.50 \\
\hline $8 / 6 / 02$ & 28,080 & 89.06 & 392.73 & 11.63 & 94.17 & 25.83 \\
\hline $8 / 7 / 02$ & 26,319 & 91.06 & 368.61 & 11.79 & 60.00 & 14.17 \\
\hline $8 / 8 / 02$ & 22,519 & 79.14 & 324.95 & 12.88 & 27.08 & \\
\hline $8 / 9 / 02$ & 26,664 & 80.83 & 377.68 & 12.73 & 87.92 & 20.00 \\
\hline $8 / 10 / 02$ & 28,492 & 88.56 & 397.38 & 12.71 & 83.75 & 52.92 \\
\hline $8 / 11 / 02$ & 25,960 & 91.47 & 368.23 & 13.46 & 98.75 & 72.92 \\
\hline $8 / 12 / 02$ & 26,665 & 90.08 & 370.86 & 12.53 & 97.08 & 8.75 \\
\hline $8 / 13 / 02$ & 26,751 & 93.03 & 373.10 & 12.26 & 97.50 & 90.42 \\
\hline $8 / 14 / 02$ & 23,453 & 93.56 & 325.74 & 11.68 & 42.08 & 39.58 \\
\hline $8 / 15 / 02$ & 21,207 & 93.69 & 295.77 & 13.43 & & \\
\hline $8 / 16 / 02$ & 20,259 & 96.39 & 299.69 & 13.55 & 49.58 & 18.75 \\
\hline $8 / 17 / 02$ & 25,856 & 93.69 & 377.46 & 13.31 & 92.50 & 90.42 \\
\hline $8 / 18 / 02$ & 24,529 & 96.81 & 377.37 & 11.19 & 97.92 & 97.50 \\
\hline $8 / 19 / 02$ & 19,187 & 92.17 & 400.56 & 12.13 & 98.33 & 74.58 \\
\hline $8 / 20 / 02$ & 21,492 & 91.33 & 447.75 & 11.08 & 99.58 & 100.00 \\
\hline $8 / 21 / 02$ & 20,759 & 86.31 & 436.11 & 10.73 & 94.17 & 97.50 \\
\hline $8 / 22 / 02$ & 16,705 & 92.97 & 350.95 & 10.85 & 63.75 & 62.50 \\
\hline $8 / 23 / 02$ & 23,453 & 89.31 & 488.60 & 11.32 & 99.17 & 100.00 \\
\hline $8 / 24 / 02$ & 20,644 & 86.08 & 449.76 & 9.98 & 80.42 & 83.33 \\
\hline $8 / 25 / 02$ & 24,132 & 92.03 & 502.75 & 10.93 & 100.00 & 100.00 \\
\hline $8 / 26 / 02$ & 23,219 & 88.64 & 492.97 & 11.69 & 94.58 & 97.50 \\
\hline
\end{tabular}




\section{Results and Discussion}

To determine the correlation, daily data from three years of plant operation was analyzed. The following constant values were determined from this data, by least-squares analysis:

A: -19.1627

B: 0.88446

C: 0.59188

D: 511.39

The previous values were then replaced in the base equation to result in the following equation:

$\mathrm{FR}=-19.1627 \mathrm{Wi}+0.88446 \mathrm{PC}_{\mathrm{OT}}+0.59188 \mathrm{RP}_{\mathrm{OT}}+511.839$

In order to verify the validity of the calculated equation, the predicted values were compared to the plant values. The following figure (figure 2) shows the resulting comparison, including the correlation coefficient (R) when a line was fitted through resulting points in the figure.

\section{Experimental Vs. Predicted Feed Rate for Iron Ore Grinding Circu it}



Figure 2: Correlation of measured plant throughput with the predicted plant throughput using the correlation derived from analysis of three years worth of plant data.

\section{Conclusions}

The capacity of the primary grinding mills was successfully predicted as a function of the ore work index, the pebble crusher usage, and the high-pressure grinding roll usage. This 
information is now available for projecting the future performance of the grinding circuit as ore characteristics change. The projected capacity will be used for determining the level of benefit that can be achieved by shifting grinding load from the secondary mill to the primary mill, using the circuit modification described in the progress report from the previous quarter.

\section{References}

L.G. Austin, R.R. Klimpel, P.T. Luckie. 1984. Process Engineering of Size Reduction: Ball Milling. Society of Mining Engineers, AIME. New York.

A.R. Laplante and J.A. Finch, 1984. The Origin of Unusual Cyclone Performance Curves. International Journal of Mineral Processing, Volume 13, p1-p11.

T.J. Napier-Munn, S. Morrel, R.D. Morrison, T. Kojovic. 1996. Mineral Comminution Circuits, Their Operation and Optimization. JKMRC Monograph Series in Mining and Mineral Processing 2. Australia.

N.L. Weiss, 1985. SME Mineral Processing Handbook. American Institute of Mining, Metallurgical and Petroleum Engineers. Volume 1, Section 2 p2-10 - p2-14.

H.J. Walqui, Mathematical Modeling of Coal Pulverizers using Population Balance Models, M.S. Thesis, Michigan Technological University, submitted August 2001.

H.J. Walqui, T.C. Eisele, and S.K. Kawatra, Development of Mathematical Models for Coal Pulverization, Presented at the SME Annual Meeting, Phoenix, AZ, Feb. 25-27, 2002 